\title{
How I do it: retrosigmoid intradural inframeatal petrosectomy
}

\author{
Torstein R. Meling ${ }^{1,2,3}$ (D) $\cdot$ Greg Zegarek $^{1} \cdot$ Karl Schaller $^{1,2}$
}

Received: 29 June 2020 / Accepted: 15 September 2020 / Published online: 28 September 2020

(C) The Author(s) 2020

\begin{abstract}
Background Lesions infiltrating the petrous temporal bone are some of the most complex to treat surgically. Many approaches have been developed in order to address these lesions, including endoscopic endonasal, anterior petrosectomy, posterior petrosectomy, and retrosigmoid.

Method We describe in a stepwise fashion the surgical steps of the retrosigmoid intradural inframeatal petrosectomy.

Conclusion The retrosigmoid intradural inframeatal petrosectomy may afford satisfactory exposure with limited drilling and minimal disruption of perilesional anatomical structures. It can provide excellent surgical results, especially for soft tumors, while minimizing surgical morbidity.
\end{abstract}

Keywords Surgery $\cdot$ Neurosurgery $\cdot$ Anatomy $\cdot$ Petrosectomy $\cdot$ Retrosigmoid $\cdot$ Brain tumor $\cdot$ Skull base

\section{Introduction}

Lesions infiltrating the petrous temporal bone are certainly among the most difficult to treat in neurosurgery. Multiple approaches have been developed in order to access the petroclival space, and which approach is chosen should be assessed on a case-by-case basis $[6,8]$. Each of these approaches, such as the endoscopic endonasal $[2,10]$, subtemporal [3], or anterior or combined petrous [5, 7] routes comes with certain built-in surgical comorbidities that must be accepted and explained to the patient [1]. We present a case of a grade II chondrosarcoma of the petrous bone (Fig. 1) operated (TRM) via the retrosigmoid intradural inframeatal

This article is part of the Topical Collection on Neurosurgery general

Electronic supplementary material The online version of this article (https://doi.org/10.1007/s00701-020-04587-0) contains supplementary material, which is available to authorized users.

Torstein R. Meling

torsteinrmeling@gmail.com

1 Division of Neurosurgery, Department of Clinical Neurosciences, Geneva University Hospitals, Geneva, Switzerland

2 Faculty of Medicine, University of Geneva, Geneva, Switzerland

3 Department of Neurological Surgery, Istituto Nazionale Neurologico "C.Besta", Milan, Italy petrosectomy (RESIP), and aim to discuss the advantages, but also the pitfalls and challenges involved.

\section{Relevant surgical anatomy}

Multiple key anatomic landmarks must be evaluated [4, 9]. We rely on craniometric landmarks adjusted based on patient individual anatomy from preoperative imaging as well as neuronavigation and augmented reality. In planning the craniotomy, the transverse (TS) and sigmoid sinus (SS) must be identified. In charting the surgical trajectory, the pneumatization of the mastoid bone, the caudal cranial nerves (CNs), the jugular bulb, the superior and inferior petrosal sinuses (SPS, IPS), the acoustico-facial bundle, the internal acoustic canal (IAC), the petrous apex, the carotid canal, and Eustachian tube must be taken into account and outlined for the use of neuronavigation and augmented reality.

\section{Description of the technique}

\section{Patient positioning and preparation}

The patient is positioned in a supine position, with elevation of the ipsilateral shoulder. The head is fixed in a Doro ${ }^{\circledR}$ headclamp and turned $100^{\circ}$ contralaterally with the vertex turned 

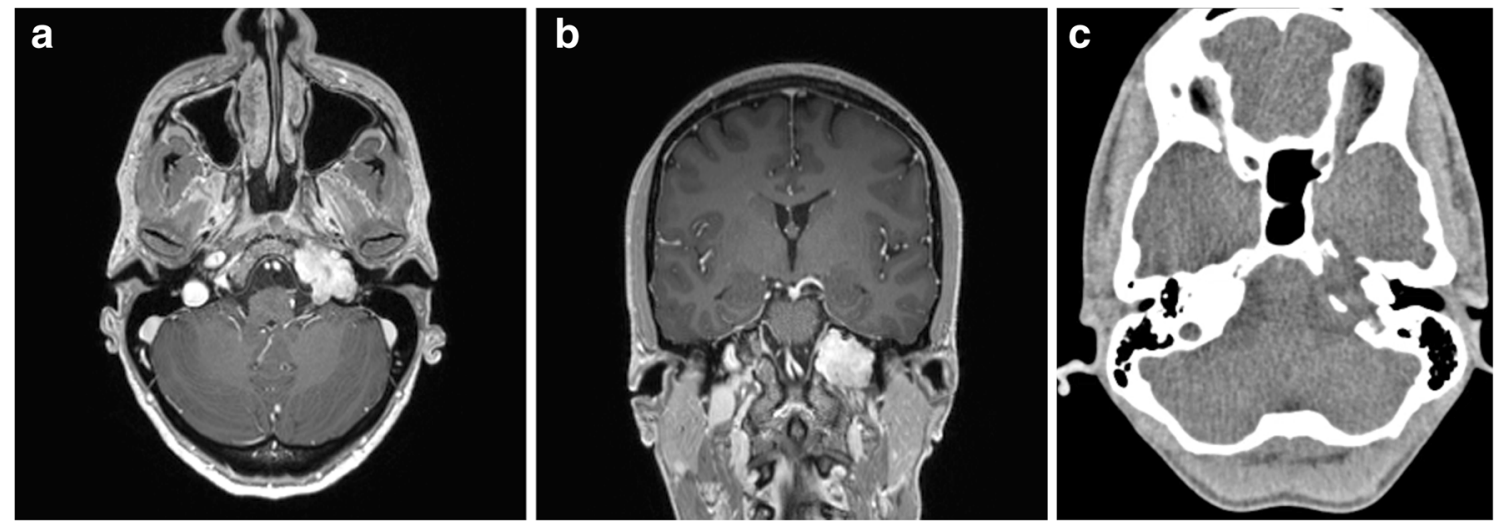

Fig. 1 Preoperative T1 Gd+ MRI demonstrating the chondrosarcoma in the petrous apex left side on axial a and coronal b cuts. Preoperative CT demonstrating the chondrosarcoma in the petrous apex left side on axial $\mathbf{c}$ cuts

slightly downwards. Brainlab® neuronavigation and augmented reality are installed, and the incision and craniotomy are planned. Markings are placed on the skin for the asterion, the trajectory of the TS and SS, and a curvilinear skin incision. Inomed ${ }^{\circledR}$ neuromonitoring is installed for auditory evoked potentials and caudal cranial nerves V-XII.

\section{Skin incision and soft tissue dissection}

After minimal shaving and standard draping, a curvilinear, retroauricular skin incision is made extending from the mastoid tip, posterior to the asterion, and superior to the TS. Using a periosteal elevator, the skin and occipital muscles are elevated, and a self-retaining retractor is placed.

\section{Retrosigmoid craniotomy}

The asterion is localized, and the TS and SS are verified with neuronavigation. A single burr hole is performed with a 50$\mathrm{mm}$ cutting burr just medial and inferior to the TS-SS junction. A $2.5 \times 3.0 \mathrm{~cm}$ craniotomy is performed. The SS and TS are further deskeletonized with the cutting burr. Mastoid air cells are opened in order to allow sufficient inferior access. The air cells are ablated with bone wax before the dural opening.

\section{Intradural dissection}

The dura is opened following a C-shaped incision along the SS. The arachnoid membrane of the posterior wall of the cerebello-medullary cistern is opened. CSF is drained by aspiration until sufficient cerebellar relaxation is achieved. The jugular foramen, the hypoglossal canal, as well as the caudal cranial nerves and the CN VII/ VIII bundle, are identified (Fig. 2).

\section{Inframeatal petrosectomy}

The inframeatal dura is identified between the internal auditory meatus and the jugular bulb. The periosteum is incised with a knife and peeled off with a Rhoton dissector \#3 (Fig. 3). A match stick 2-mm sharp burr (Medtronic ${ }^{\circledR}$ T9MH20 drill bit) is utilized to remove the bone overlying the tumor and then up to unfloor the IAC with visualization of the CN VII/VIII bundle (Fig. 4). The trajectory towards the petrous apex anteromedially is utilized.

\section{Tumor resection}

The surgical corridor begins inferiorly to the CN VII/VIII bundle with a trajectory medial to the semicircular canals and the fallopian canal. In addition, the greater superficial, lesser petrosal, and deep petrosal nerves are protected. The resection terminates on reaching the carotid canal.

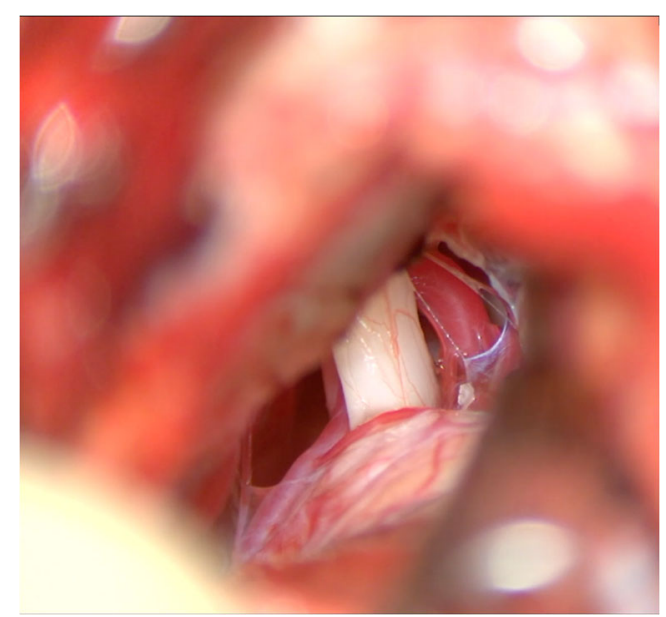

Fig. 2 The dura has been incised and the CN VII/VIII bundle is identified as well as the AICA 


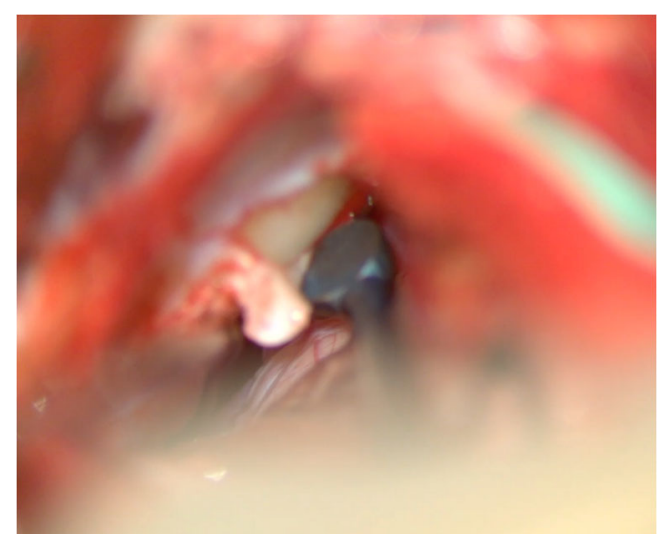

Fig. 3 The dura overlying the inframeatal petrous bone is incised and dissected

In this case, the tumor was quite soft, wherefore resection was performed by aspiration and angled curettes (Fig. 5). The cavity can be inspected and the resection can be completed under visual guidance using an endoscope.

Important venous bleeding might be encountered from the IPS during tumor resection which is controlled by Sutter ${ }^{\circledR}$ bipolar electrocautery or Gelfoam ${ }^{\circledR}$, compression, and irrigation.

The inframeatal approach affords a sufficient surgical corridor from a simple retrosigmoid craniotomy while precipitating less surgical comorbidity compared with anterior petrosectomy $[1,10]$ or endoscopic endonasal approaches.

\section{Closure}

The dural defect over the jugular foramen is closed with TachoSeal ${ }^{\circledR}$. Water-tight dural closure is performed with Monocryl 5.0 running suture. Mastoid air cells are closed again with bone wax. The bone flap is repositioned using

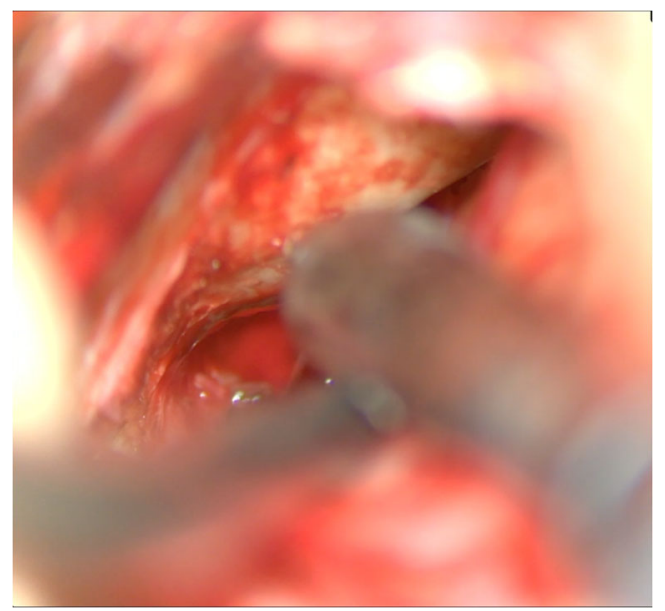

Fig. 4 The inframeatal bone is drilled to expose the exophytic portion of the tumor. Drilling is continued towards the IAC until exposure of $\mathrm{CN}$ $\mathrm{VII} / \mathrm{VIII}$ is achieved

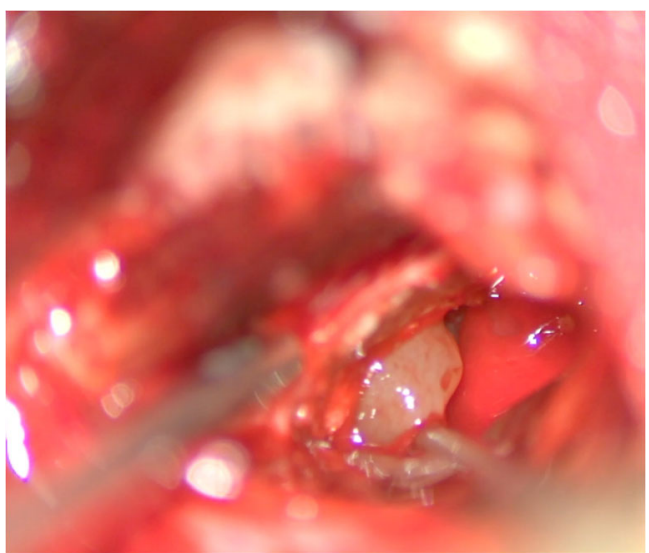

Fig. 5 Tumor resection by angled curettes and aspiration is performed. The anterior limit of tumor resection is the petrous segment of the internal carotid artery

Stryker ${ }^{\circledR}$ titanium microplates and $4 \mathrm{~mm}$ self-tapping screws. Mastoid air cells are again closed with bone wax. Muscle and skin are closed with a running Monocryl 2.0 suture.

\section{Postoperative course}

Postoperatively, our patient had an uneventful recovery with no $\mathrm{CN}$ deficits and no complications. She was mobilized the first postoperative day, and an MRI demonstrated a near-total resection of her chondrosarcoma (Fig. 6).

\section{Indications}

Smaller petroclival tumors or larger soft or cystic petroclival lesions.

\section{Limitations}

Upper petrous ridge tumors are limited by acoustic-facial bundle. Venous anatomy in case of high jugular bulb position precludes any drilling under and behind the acoustico-facial porus.

\section{How to avoid complications}

- Careful preoperative anatomic study

- Augmented reality aid the surgical planning

- Meticulous microsurgical technique

- Cranial nerve neuromonitoring

- Careful closure to avoid CSF leak 
Fig. 6 Postoperative imaging demonstrating near-total resection of the chondrosarcoma in the petrous apex left side on axial T1 $\mathrm{Gd}+\mathrm{MRI}$ subtraction series (a) and CT (b)
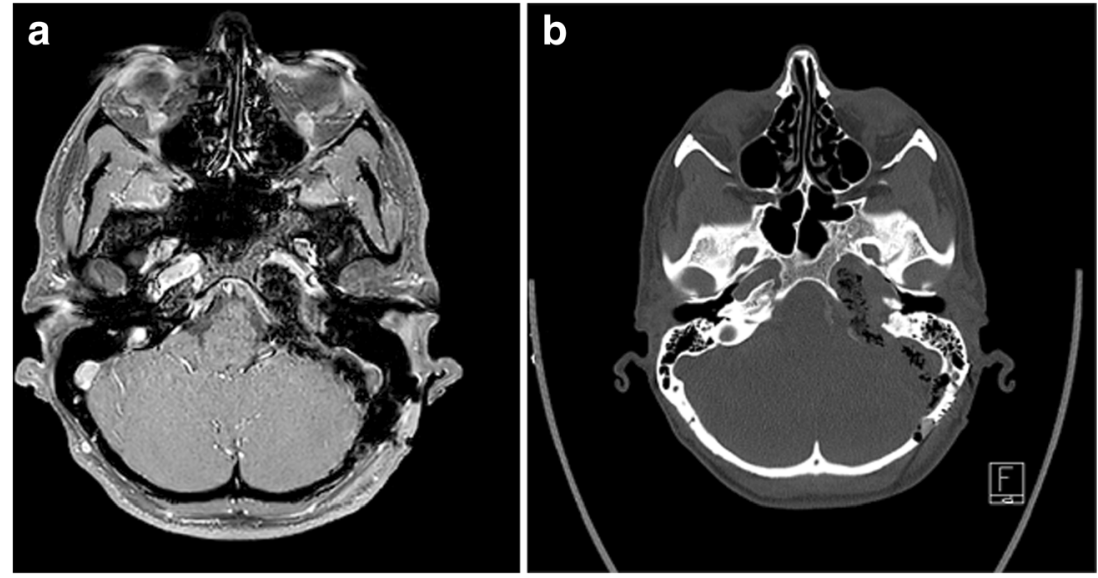

\section{Specific perioperative considerations}

\section{Preoperative workup}

- Complete ENT workup

- MRI and high-definition CT of the skull base including angiography and venography

- Neuronavigation and augmented reality facilitates preoperative planning

\section{Postoperative care}

- Bed rest overnight

- Head of bed at $30^{\circ}$

- Prophylactic anticoagulation to be started first postoperative day

- Systolic blood pressure below $120 \mathrm{mmHg}$

- Control MRI first postoperative day

- Multidisciplinary discussion at skull base tumor board
Acknowledgments The authors would like to thank Philippe Bijlenga, $\mathrm{MD}, \mathrm{PhD}$, for the augmented reality data.

Funding Open access funding provided by University of Geneva.

\section{Compliance with ethical standards}

Conflict of interest The authors declare that they have no conflict of interest.

Open Access This article is licensed under a Creative Commons Attribution 4.0 International License, which permits use, sharing, adaptation, distribution and reproduction in any medium or format, as long as you give appropriate credit to the original author(s) and the source, provide a link to the Creative Commons licence, and indicate if changes were made. The images or other third party material in this article are included in the article's Creative Commons licence, unless indicated otherwise in a credit line to the material. If material is not included in the article's Creative Commons licence and your intended use is not permitted by statutory regulation or exceeds the permitted use, you will need to obtain permission directly from the copyright holder. To view a copy of this licence, visit http://creativecommons.org/licenses/by/4.0/.

\section{References}

1. Bernard F, Troude L, Isnard S, Lemee JM, Terrier LM, Francois P, Velut S, Gay E, Fournier HD, Roche PH (2019) Long term surgical results of 154 petroclival meningiomas: a retrospective multicenter study. Neurochirurgie 65: 55-62. https://doi.org/10.1016/j.neuchi.2019.02.001

2. Borghei-Razavi H, Truong HQ, Fernandes Cabral DT, Sun X, Celtikci E, Wang E, Snyderman C, Gardner PA, FernandezMiranda JC (2019) Endoscopic endonasal petrosectomy: anatomical investigation, limitations, and surgical relevance. Oper Neurosurg (Hagerstown) 16:557-570. https://doi.org/10.1093/ons/ opy 195

3. Chiaramonte C, Jacquesson T, Jouanneau E (2019) Extra-intradural extracavernous subtemporal approach for chondrosarcomas: technical note and case report. Acta Neurochir 161:2349-2352. https:// doi.org/10.1007/s00701-019-03989-z

4. Constanzo F, Gerhardt J, Ramina R (2019) How I do it: retrosigmoid suprajugular approach to the jugular foramen. Acta 
Neurochir 161:2271-2274. https://doi.org/10.1007/s00701-01904030-z

5. Hanakita S, Watanabe K, Champagne PO, Froelich S (2019) How I do it: combined petrosectomy. Acta Neurochir 161:2343-2347. https://doi.org/10.1007/s00701-019-04022-z

6. Jacquesson T, Berhouma M, Tringali S, Simon E, Jouanneau E (2015) Which routes for petroclival tumors? A comparison between the anterior expanded endoscopic endonasal approach and lateral or posterior routes. World Neurosurg 83: 929-936. https://doi.org/10.1016/j.wneu.2015.02.003

7. Roche PH, Lubrano VF, Noudel R (2011) How I do it: epidural anterior petrosectomy. Acta Neurochir 153:1161-1167. https://doi. org/10.1007/s00701-011-1010-9

8. Samii M, Metwali H, Samii A, Gerganov V (2013) Retrosigmoid intradural inframeatal approach: indications and technique. Neurosurgery 73:ons53-ons59; discussion ons60. https://doi.org/10.1227/NEU.0b013e3182889e59

9. Troude L, Bernard F, Sy ECN, Roche PH (2019) The modified retrosigmoid approach: a how I do it. Acta Neurochir 161:417423. https://doi.org/10.1007/s00701-018-3764-9

10. Van Gompel JJ, Alikhani P, Tabor MH, van Loveren HR, Agazzi S, Froelich S, Youssef AS (2014) Anterior inferior petrosectomy: defining the role of endonasal endoscopic techniques for petrous apex approaches. J Neurosurg 120: 1321-1325. https://doi.org/10.3171/2014.2.JNS131773
Key points

- The retrosigmoid intradural inframeatal petrosectomy (RESIP) approach is minimal invasive.

- The RESIP is direct and quick because of limited drilling and minimal disruption of perilesional anatomical structures.

- The RESIP is a valid alternative to approach carefully selected lesions, where the endoscopic, endonasal or anterior petrosectomies would be more invasive, complicated or dangerous.

- In-depth knowledge of petrous bone anatomy is crucial.

- Preoperative images must be carefully assessed.

- Neuronavigation and augmented reality facilitates preoperative planning

- Intraoperative cranial nerve monitoring is mandatory.

- Careful patient positioning and CSF drainage for cerebellar relaxation obviates the need for rigid retractors.

- The cavity can be inspected and the resection can be completed under visual guidance using an endoscope.

- There is no need for complex dura repairs or bony reconstructions as with endoscopic, endonasal or anterior petrosectomies.

Publisher's note Springer Nature remains neutral with regard to jurisdictional claims in published maps and institutional affiliations. 